\title{
Impact of the COVID-19 Epidemic on Lifestyle Behaviors and Their Association With Subjective Well-Being Among the General Population in Mainland China: Cross-Sectional Study
}

Zhao $\mathrm{Hu}^{1}$, MD; Xuhui $\mathrm{Lin}^{1}$, MD; Atipatsa Chiwanda Kaminga ${ }^{2,3}$, MD; Huilan $\mathrm{Xu}^{1}$, $\mathrm{PhD}$

\footnotetext{
${ }^{1}$ Department of Social Medicine and Health Management, Xiangya School of Public Health, Central South University, Changsha, China

${ }^{2}$ Department of Mathematics and Statistics, Mzuzu University, Luwinga, Mzuzu, Malawi

${ }^{3}$ Department of Epidemiology and Health Statistics, Xiangya School of Public Health, Central South University, Changsha, China
}

\section{Corresponding Author:}

Huilan $\mathrm{Xu}, \mathrm{PhD}$

Department of Social Medicine and Health Management

Xiangya School of Public Health

Central South University

238 Shangmayuanling

Changsha, 410078

China

Phone: 86073184135459

Email:xhl6363@sina.com

\section{Abstract}

Background: The world is experiencing an unprecedented challenge due to the coronavirus disease (COVID-19) pandemic. However, it is unclear whether people's lifestyles will change as a result.

Objective: The aim of this study is to explore perceived lifestyle changes after the outbreak of COVID-19 and their association with subjective well-being (SWB) among the general population in Mainland China.

Methods: An online survey was conducted in May 2020. Lifestyle behaviors including leisure-time physical exercise, leisure-time screen time, and dietary intake were self-reported. SWB was measured using the General Wellbeing Schedule (GWS). Other covariates including sociodemographic factors, self-rated physical health, perceived social support, and loneliness were also assessed by a structured questionnaire. A multivariate ordinal regression method was used to analyze the association between SWB and lifestyle behaviors as well as perceived lifestyle changes.

Results: A total of 1033 participants aged between 18 and 60 years were included in this study. The mean GWS score was 71.7 points. About $70 \%$ of the respondents reported spending more time looking at screens, whereas about $30 \%$ reported an increased frequency of vegetable and fruit intake after the outbreak of COVID-19. Inactive physical exercise (odds ratio [OR] 1.16, 95\% CI 1.02-1.48), infrequent vegetable intake (OR 1.45, 95\% CI 1.10-1.90), infrequent fruit intake (OR 1.31, 95\% CI 1.01-1.70), and often skipping breakfast (OR 1.43, 95\% CI 1.08-1.91) were associated with lower SWB after adjusting for sociodemographic factors, self-rated physical health, perceived social support, and loneliness. Moreover, participants who perceived a decrease in the frequency of vegetable, fruit, and breakfast intake were more likely to report lower SWB.

Conclusions: The COVID-19 pandemic may have positive and negative impacts on different aspects of lifestyle behaviors. Both unhealthy lifestyle behaviors and negative lifestyle changes were associated with lower SWB. These findings provide scientific evidence that can inform lifestyle guidelines and public mental health interventions during the COVID-19 outbreak.

(J Med Internet Res 2020;22(8):e21176) doi: $10.2196 / 21176$

\section{KEYWORDS}

COVID-19; coronavirus disease; subjective well-being; lifestyle behaviors 


\section{Introduction}

The ongoing coronavirus disease (COVID-19) outbreak has led to an unprecedented public health crisis worldwide [1]. COVID-19, similar to severe acute respiratory syndrome (SARS), is a beta-coronavirus that can be spread to humans through intermediate hosts such as bats [2]. The COVID-19 outbreak was first revealed in late December 2019 in Wuhan, Hubei Province, China. On January 30, 2020, the World Health Organization (WHO) declared the COVID-19 outbreak a public health emergency of international concern [3]. In the following months, COVID-19 spread rapidly in China and worldwide.

At the same time, the global population is experiencing life-altering challenges due to the COVID-19 pandemic [4]. Given the lack of effective treatment for COVID-19, nonpharmacological interventions (NPIs) are required to decrease its transmission [5]. In essence, NPIs are intended to modify disease-related lifestyle behaviors such that these should no longer contribute to the spread of the disease. However, lifestyle choices or behavioral change may lead to unforeseen detrimental or protective consequences for mental health outcomes [6-10]. For example, some NPIs, such as personal restrictions, mass confinement, and compulsory home isolation, may be associated with worse psychological conditions [8], whereas some NPIs, such as good ventilation in the workplace and wearing a face mask, were found to be protective of mental health during the COVID-19 pandemic $[9,10]$. Furthermore, evidence from recent studies suggests that current pandemic-related coping strategies may have an adverse impact on mental health, such as decreased well-being and increased posttraumatic stress disorders (PTSD), depression and anxiety symptoms, insomnia, and anger [11-13]. In addition, fear of the disease and social isolation may lead to stress reactions that could develop into other psychological disorders [14].

Unhealthy lifestyle habits such as poor diet, lack of physical activity, smoking, and alcohol use are not only major contributors to the global burden of disease [15], but are also positively associated with worse mental health outcomes [16]. Recently, lifestyle guidelines have emphasized maintaining a healthy nutritional status and engaging in physical exercise at home during the COVID-19 outbreak [17,18]. Many other studies have suggested that the focus should be on addressing the mental health aspect when implementing public disease control and prevention interventions [19,20]. However, observational studies on the characteristics of behavior patterns such as dietary intake, physical exercise, and screen time among the general population after the outbreak of COVID-19 are lacking [21]. Similarly, data about perceived lifestyle changes among the general population after the outbreak of COVID-19 are also lacking. Moreover, the associations between mental health outcomes and lifestyle behaviors as well as lifestyle changes during the COVID-19 pandemic represent a research gap.

Therefore, this study aimed to explore the perceived lifestyle changes after the outbreak of COVID-19, and their association with subjective well-being among the general population in Mainland China. It is hoped that, from the public health and preventative care perspectives, this study can provide valuable information to inform public health policies or interventions aimed at maintaining good mental health and a healthy lifestyle during the COVID-19 pandemic.

\section{Methods}

\section{Overview}

This study was conducted from May 10 to May 15, 2020, through an online survey using an internet platform [22]. This platform has more than 2.6 million members distributed across more than 30 provinces in China, of which $52.00 \%$ are female, $29.34 \%$ are aged 26 to 30 years, and $39.20 \%$ are general staff. All participants signed an online informed consent form before filling out this questionnaire. The target population comprised all Chinese people in Mainland China aged between 18 and 60 years. A computer-assisted simple random sampling method was used to select eligible participants from this internet platform. Adolescents were not interviewed because it would be difficult to obtain parental consent over the internet, and older adults ( $\geq 60$ years old) were not investigated as recall bias may be strong in this group. Participants were also excluded if they refused to participate in this survey, did not reply, or could not complete the online survey independently.

\section{Data Collection}

\section{Sociodemographic Information}

A self-administrated structured questionnaire was used to collect the participants' sociodemographic information including age, gender (male or female), residential location (urban or rural area), marital status (married or unmarried), education (high school and below, college or university degree, master's degree and above) and personal monthly income. The unmarried group included those who were divorced, single, and widowed.

\section{Lifestyle Behaviors Assessment}

Lifestyle behaviors in the 4 months immediately before and the 4 months immediately after the COVID-19 outbreak were assessed. In addition, the perceived lifestyle changes after the COVID-19 outbreak were assessed in relation to lifestyle behaviors in the 4 months before the COVID-19 outbreak. The specific lifestyle behaviors that were assessed included the following: leisure-time physical exercise, leisure-time screen time, and dietary intake. To measure leisure-time physical exercise, four items from the long version of the International Physical Activity Questionnaire (IPAQ), a valid and reliable questionnaire assessing physical activity [23], were used. Of the four items, two assess the frequency of moderate or vigorous physical exercise (such as running and dancing) per week and the other two items assess the duration of physical exercise every time. Participants were defined as active if they reported a total moderate-vigorous physical exercise time of more than 150 minutes/week [24]. The Cronbach $\alpha$ of these items in this study was 0.685 . Leisure-time screen time was viewed as a major indicator of sedentary behavior, and was calculated by summing up the screen time related to watching TV/videos, internet use (such as news and Douban) through a smartphone or the internet, playing computer or smartphone games, studying online, and social platform use (such as QQ and Wechat). 
Leisure-time screen time was further classified as short $(<2$ hours/day) and long ( $\geq 2$ hours/day). Three items from the simplified food frequency questionnaire (FFQ-25) [25] were used to assess the weekly frequency of consuming vegetables (including light- and deep-colored vegetables) and fruits (such as apples and pears). Thus, participants were dichotomized as frequently ( $\geq 5$ times/week) and infrequently ( $<5$ times/week) consuming fruits and vegetables. The Cronbach $\alpha$ of these items in this study was 0.725 . The question "How many days do you skip breakfast weekly after the outbreak of COVID-19?" was used to assess the frequency of skipping breakfast and this dichotomized participants as seldom ( $<3$ days/week) and often ( $\geq 3$ days/week). Perceived lifestyle changes compared to lifestyle behaviors before the outbreak of COVID-19 were classified into three categories as follows: increased or much increased, same as before, and decreased or much decreased.

\section{Covariates}

Other covariates assessed were self-rated physical health, perceived social support (PSS), and loneliness during the COVID-19 epidemic. Self-rated physical health was assessed using a 5-item Likert scale. For example, one of the questions asked, "How do you feel about your physical condition?" Participants rated their physical condition as good, fair, or poor. PSS was measured using the Chinese version of the Perceived Social Support Scale (PSSS). The PSSS was developed by Zimet in 1988 [26] and was used to measure PSS from three sources: family, friends, and significant others. This scale contain 12 items, scored on a 7-point rating scale from 1 (very strongly disagree) to 7 (very strongly agree). The total score ranges from 12 to 84, and PSS is divided into low (a score from 12 to 36), intermediate (a score from 37 to 60), and high (a score from 61 to 84 ). The Cronbach $\alpha$ of this scale in this study was 0.881 . Loneliness was measured using the short from of the University of California, Los Angeles (UCLA) Loneliness Scale (ULS-8) [27], which was adapted by Hays and DiMatteo in 1987 on the basis of UCLA-20 [28]. This scale contains 8 items and the total score ranges from 8 to 32, with higher scores indicating higher levels of loneliness. The loneliness of participants was classified into three levels (low, intermediate, and high) according to the tertile of total score of ULS-8. The Cronbach $\alpha$ of this scale in this study was 0.818 .

\section{Subjective Well-Being Assessment}

Subjective well-being (SWB), a main indicator of mental health, is a broad category of phenomena that includes people's emotional response, domain satisfaction, and global judgments of life satisfaction [29]. SWB was measured using the Chinese adapted version of the General Wellbeing Schedule (GWS) [30], which was first developed by the US National Center for Health Statistics in 1977. It contains the following 6 dimensions: satisfaction and interest in life; health concerns; energy; depression or pleasant mood; control of emotions and behavior; and relaxation and tension. The total scores for this instrument are yielded by summing up the items' scores, with higher scores indicating higher levels of SWB. The SWB of participants was classified into three levels (high, intermediate, and low) according to the tertile of total scores on the GWS. The GWS has high reliability and validity in the Chinese population, with a Cronbach of 0.91 and 0.95 for men and women, respectively [30]. The Cronbach $\alpha$ of this scale in this study was 0.812 .

\section{Statistical Analysis}

Categorical variables were summarized as counts and percentages, while continuous variables were summarized as mean and standard deviation. The statistical difference in the distribution of the GWS scores across different sociodemographic characteristics and lifestyle behaviors was assessed using the Student $t$ test or the one-way analysis of variance (ANOVA). The statistical difference in the distribution of perceived lifestyle changes across different groups was assessed using the chi-square test. Multivariate ordinal regression models were used to explore the association between SWB (1=low; 2=intermediate; 3=high) and lifestyle behaviors as well as perceived lifestyle changes. The strength of association was reported as odds ratio (OR) and 95\% CI. An unadjusted relationship between SWB and each lifestyle behavior as well as its change was examined in Model 1 (crude model), whereas an adjusted relationship between SWB and each lifestyle behavior as well as its change was examined in Model 2, adjusted for the variables age, gender, education, marital status, residential location, and personal monthly income. Finally, a relationship between SWB and each lifestyle behavior as well as its change was examined in Model 3, which adjusted for covariates including self-rated physical health, perceived social support, loneliness, and all the covariates entered in Model 2. The statistical analyses were conducted in SPSS (Version 22.0; IBM Corp). All statistical tests were two-tailed and a $P<.05$ was considered statistically significant.

\section{Results}

A total of 1600 registrants were invited to take part in this online survey and a total of 1081 subjects consented to take part in the study, providing a response rate of $67.6 \%$. The main reasons for nonresponse were declining to participate and no reply. After excluding 48 participants due to an incomplete questionnaire or missing data, a total of 1033 participants were included in this study. Among them, 637 participants were aged between 18 and 30 years $(61.7 \%)$ and 498 were female (48.2\%). Further, a very small proportion of the participants $(n=95,9.2 \%)$ had attended high school and lower levels of education. In addition, 730 subjects $(70.7 \%)$ were living in urban areas, 846 participants $(81.9 \%)$ considered their physical health status as good, and 675 participants $(65.3 \%)$ felt that they had been receiving high social support. Regarding lifestyle, 58.8\% ( $n=607)$ of the participants had leisure-time physical exercise of more than 150 $\mathrm{min} /$ week, about $86.8 \%(\mathrm{n}=897)$ had screen time of 2 hours/day or more, and $67.9 \%(\mathrm{n}=701)$ ate vegetables 5 times/week or more, whereas $41.8 \%(n=432)$ of the subjects ate fruits 5 times/week or more. Characteristics of participants are summarized in Table 1.

The mean GWS score in this sample was 71.7 points (SD 12.5). In addition, the distribution of GWS scores was not significantly different across the categories of gender, education, and leisure-time screen time $(P>.05)$. Table 1 shows the details. 
Table 1. Distribution of sample characteristics and General Wellbeing Schedule scores.

\begin{tabular}{|c|c|c|c|}
\hline Characteristics & Participants, n (\%) & General Wellbeing Schedule score, mean (SD) & $P$ value $^{\mathrm{a}}$ \\
\hline \multicolumn{4}{|l|}{ Age (years) } \\
\hline $18-30$ & $637(61.7)$ & $70.9(12.1)$ & .03 \\
\hline $31-40$ & $281(27.2)$ & $72.3(12.6)$ & $\mathrm{N} / \mathrm{A}^{\mathrm{b}}$ \\
\hline$\geq 41$ & $115(11.1)$ & $74.1(14.3)$ & N/A \\
\hline \multicolumn{4}{|l|}{ Gender } \\
\hline Male & $535(51.8)$ & $71.8(12.2)$ & .68 \\
\hline Female & $498(48.2)$ & $71.5(12.9)$ & N/A \\
\hline \multicolumn{4}{|l|}{ Residential location } \\
\hline Urban & $730(70.7)$ & $72.6(12.5)$ & $<.001$ \\
\hline Rural & $303(29.3)$ & $69.5(12.4)$ & N/A \\
\hline \multicolumn{4}{|l|}{ Education } \\
\hline High school and below & $95(9.2)$ & $69.5(12.2)$ & .06 \\
\hline College or university degree & $858(83.1)$ & $71.7(12.5)$ & N/A \\
\hline Master's degree and above & $80(7.7)$ & $74.1(12.5)$ & N/A \\
\hline \multicolumn{4}{|l|}{ Marital status } \\
\hline Married & $485(47.0)$ & $73.2(12.4)$ & $<.001$ \\
\hline Unmarried & $548(53.0)$ & $69.9(12.5)$ & N/A \\
\hline \multicolumn{4}{|l|}{ Personal monthly income (¥) } \\
\hline$<3000$ & $283(27.4)$ & $69.2(12.4)$ & $<.001$ \\
\hline $3000-7999$ & $471(45.6)$ & $71.2(12.4)$ & N/A \\
\hline$\geq 8000$ & $279(27.0)$ & $74.9(12.3)$ & N/A \\
\hline \multicolumn{4}{|l|}{ Self-rated physical health } \\
\hline Good & $846(81.9)$ & $73.6(11.8)$ & $<.001$ \\
\hline Fair & $177(17.1)$ & $63.4(12.0)$ & N/A \\
\hline Poor & $10(1.0)$ & $54.7(11.6)$ & N/A \\
\hline \multicolumn{4}{|l|}{ Perceived social support } \\
\hline High & $675(65.3)$ & $75.7(12.5)$ & $<.001$ \\
\hline Intermediate & 340 (32.9) & $64.8(11.3)$ & N/A \\
\hline Low & $18(1.8)$ & $52.3(16.3)$ & N/A \\
\hline \multicolumn{4}{|l|}{ Loneliness } \\
\hline High & $340(32.9)$ & $81.0(9.3)$ & $<.001$ \\
\hline Intermediate & $387(37.5)$ & $71.1(10.1)$ & N/A \\
\hline Low & $306(29.6)$ & $62.0(10.7)$ & N/A \\
\hline \multicolumn{4}{|l|}{ Leisure-time physical exercise } \\
\hline Active & $607(58.8)$ & $72.9(12.4)$ & $<.001$ \\
\hline Inactive & $426(41.2)$ & $69.9(12.6)$ & N/A \\
\hline \multicolumn{4}{|l|}{ Leisure-time screen time } \\
\hline Short & $136(13.2)$ & $72.1(14.0)$ & .64 \\
\hline Long & $897(86.8)$ & $71.6(12.3)$ & N/A \\
\hline \multicolumn{4}{|l|}{ Frequency of vegetable intake } \\
\hline Infrequently & $332(32.1)$ & $69.2(12.1)$ & $<.001$ \\
\hline
\end{tabular}




\begin{tabular}{llll}
\hline Characteristics & Participants, $\mathrm{n}(\%)$ & General Wellbeing Schedule score, mean (SD) & $P$ value ${ }^{\mathrm{a}}$ \\
\hline \multicolumn{1}{c}{ Frequently } & $701(67.9)$ & $72.8(12.6)$ & N/A \\
$\begin{array}{l}\text { Frequency of fruit intake } \\
\quad \text { Infrequently }\end{array}$ & $601(58.2)$ & $69.8(12.0)$ & $<.001$ \\
$\quad$ Frequently & $432(41.8)$ & $74.2(12.8)$ & N/A \\
Frequency of skipping breakfast & & & $<.001$ \\
$\quad$ Seldom & $721(69.8)$ & $73.4(12.5)$ & N/A \\
$\quad 312(30.2)$ & $67.7(11.7)$ & \\
\hline
\end{tabular}

${ }^{\mathrm{a}} P$ values were obtained according to the Student $t$ test or one-way analysis of variance.

${ }^{\mathrm{b}} \mathrm{N} / \mathrm{A}$ : not applicable.

Furthermore, about $17.0 \%$ of the respondents stated that they spent more time doing physical exercise, and about $2 / 3$ of the respondents reported that they spent more time looking at screens. Additionally, a small proportion of participants decreased the frequency of their intake of vegetables, fruits, and breakfast. In addition, changes in the frequency of fruit and breakfast intake were associated with participants' residential locations. There were no statistical differences in perceived lifestyle changes associated with gender. These results are shown in Table 2.

Table 2. Perceived lifestyle changes by gender and place of residence.

\begin{tabular}{|c|c|c|c|c|c|c|c|}
\hline \multirow[t]{2}{*}{ Lifestyle habits } & \multirow[t]{2}{*}{ Overall, $\%$} & \multicolumn{3}{|l|}{ Gender } & \multicolumn{3}{|c|}{ Place of residence } \\
\hline & & Male, $\%$ & Female, $\%$ & $P$ value $^{\mathrm{a}}$ & Urban, \% & Rural, \% & $P$ value $^{\mathrm{a}}$ \\
\hline \multicolumn{8}{|l|}{ Time spent exercising } \\
\hline Increased or much increased & 17.8 & 18.5 & 17.1 & .12 & 18.6 & 19.5 & .36 \\
\hline Same as before & 63.3 & 65.1 & 61.4 & $\mathrm{~N} / \mathrm{A}^{\mathrm{b}}$ & 62.5 & 65.3 & N/A \\
\hline Decreased or much decreased & 18.9 & 16.4 & 21.5 & N/A & 18.9 & 15.2 & N/A \\
\hline \multicolumn{8}{|l|}{ Time spent looking at screens } \\
\hline Increased or much increased & 68.3 & 65.2 & 71.5 & .09 & 70.0 & 64.0 & .12 \\
\hline Same as before & 23.9 & 25.8 & 21.9 & N/A & 23.0 & 26.1 & N/A \\
\hline Decreased or much decreased & 7.8 & 9.0 & 6.6 & N/A & 7.0 & 9.9 & N/A \\
\hline \multicolumn{8}{|l|}{ Frequency of vegetable intake } \\
\hline Increased or much increased & 28.8 & 28.4 & 29.1 & .32 & 29.2 & 27.7 & .89 \\
\hline Same as before & 55.8 & 54.6 & 57.2 & N/A & 55.5 & 56.8 & N/A \\
\hline Decreased or much decreased & 15.4 & 17.0 & 13.7 & N/A & 15.3 & 15.5 & N/A \\
\hline \multicolumn{8}{|l|}{ Frequency of fruit intake } \\
\hline Increased or much increased & 35.3 & 36.7 & 33.9 & .21 & 37.1 & 31.0 & .004 \\
\hline Same as before & 46.0 & 46.7 & 45.2 & N/A & 46.7 & 44.2 & N/A \\
\hline Decreased or much decreased & 18.7 & 16.6 & 20.9 & N/A & 16.2 & 24.8 & N/A \\
\hline \multicolumn{8}{|l|}{ Frequency of skipping breakfast } \\
\hline Increased or much increased & 23.1 & 20.2 & 26.1 & .06 & 23.4 & 22.1 & .02 \\
\hline Same as before & 56.9 & 58.1 & 55.6 & N/A & 58.8 & 52.5 & N/A \\
\hline Decreased or much decreased & 20.0 & 21.7 & 18.3 & N/A & 17.8 & 25.4 & N/A \\
\hline
\end{tabular}

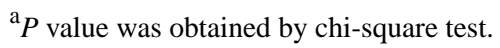

${ }^{\mathrm{b}} \mathrm{N} / \mathrm{A}$ : not applicable.

The association between lifestyle behaviors during the COVID-19 pandemic and subjective well-being among the general population in Mainland China is summarized in Table 3. The multivariate ordinal regression model showed that participants with inadequate leisure-time physical exercise (OR $1.16,95 \%$ CI 1.02-1.48), infrequent vegetable intake (OR 1.45, 95\% CI 1.10-1.90), infrequent fruit intake (OR 1.31, 95\% CI 1.01-1.70), as well as those who often skipped breakfast (OR 
$1.43,95 \%$ CI 1.08-1.91) were associated with a higher risk of lower subjective well-being after adjusting for age, gender, education, marital status, residential location, personal monthly income, self-rated physical health, perceived social support, and loneliness.
The association between perceived lifestyle changes, before and after the outbreak of COVID-19, and subjective well-being is summarized in Table 4. An ordinal regression model indicated that participants with decreased frequency of vegetable and fruit intake, and increased frequency of skipping breakfast were more likely to report lower subjective well-being after adjusting for sociodemographic factors and other covariates.

Table 3. The association between lifestyle behaviors and subjective well-being.

\begin{tabular}{|c|c|c|c|}
\hline Lifestyle behaviors & Model $1, \mathrm{OR}^{\mathrm{a}}(95 \% \mathrm{CI})$ & Model $2^{\mathrm{b}}$, OR $(95 \% \mathrm{CI})$ & Model $3^{\mathrm{c}}$, OR $(95 \% \mathrm{CI})$ \\
\hline \multicolumn{4}{|c|}{ Leisure-time physical exercise } \\
\hline Active & 1.00 & 1.00 & 1.00 \\
\hline Inactive & $1.51(1.20-1.89)$ & $1.42(1.12-1.79)$ & $1.16(1.02-1.48)$ \\
\hline \multicolumn{4}{|c|}{ Leisure-time screen time } \\
\hline Short & 1.00 & 1.00 & 1.00 \\
\hline Long & $1.12(0.81-1.57)$ & $1.09(0.78-1.53)$ & $1.37(0.94-1.99)$ \\
\hline \multicolumn{4}{|c|}{ Frequency of vegetable intake } \\
\hline Frequently & 1.00 & 1.00 & 1.00 \\
\hline Infrequently & $1.82(1.41-2.30)$ & $1.81(1.41-2.31)$ & $1.45(1.10-1.90)$ \\
\hline \multicolumn{4}{|c|}{ Frequency of fruit intake } \\
\hline Frequently & 1.00 & 1.00 & 1.00 \\
\hline Infrequently & $1.88(1.49-2.37)$ & $1.70(1.34-2.14)$ & $1.31(1.01-1.70)$ \\
\hline \multicolumn{4}{|c|}{ Frequency of skipping breakfast } \\
\hline Seldom & 1.00 & 1.00 & 1.00 \\
\hline Often & $2.28(1.78-2.92)$ & $2.12(1.64-2.73)$ & $1.43(1.08-1.91)$ \\
\hline
\end{tabular}

${ }^{\mathrm{a} O R}$ : odds ratio.

${ }^{\mathrm{b}}$ Adjusted for age, gender, marital status, residential location, education, and personal monthly income.

${ }^{\mathrm{c}}$ Adjusted for covariates in Model 2 and plus self-rated physical health, perceived social support, and loneliness.

Table 4. The association between perceived lifestyle changes and subjective well-being.

\begin{tabular}{llll}
\hline Perceived lifestyle changes & Model 1, OR ${ }^{\mathrm{a}}(95 \% \mathrm{CI})$ & Model 2 $^{\mathrm{b}}, \mathrm{OR}(95 \% \mathrm{CI})$ & Model 3 $^{\mathrm{c}}, \mathrm{OR}(95 \% \mathrm{CI})$ \\
\hline Decreased time spent exercising & $1.15(0.85-1.54)$ & $1.14(0.86-1.56)$ & $1.11(0.80-1.54)$ \\
Increased time spent looking at screens & $1.33(1.05-1.69)$ & $1.32(0.98-1.60)$ & $1.03(0.80-1.34)$ \\
Decreased frequency of vegetable intake & $1.84(1.34-2.53)$ & $1.78(1.30-2.44)$ & $1.73(1.21-2.46)$ \\
Decreased frequency of fruit intake & $1.56(1.16-2.08)$ & $1.48(1.10-1.98)$ & $1.41(1.02-1.96)$ \\
Increased frequency of skipping breakfast & $2.05(1.45-2.88)$ & $1.83(1.29-2.59)$ & $1.49(1.01-2.18)$ \\
\hline
\end{tabular}

${ }^{\mathrm{a} O R}$ : odds ratio.

${ }^{\mathrm{b}}$ Adjusted for age, gender, marital status, residential location, education, and personal monthly income.

${ }^{\mathrm{c}}$ Adjusted for covariates in Model 2 and plus self-rated physical health, perceived social support, and loneliness.

\section{Discussion}

Previous studies have predominantly focused on the psychological impact of the COVID-19 epidemic, rather than lifestyle issues. For the first time, some perceived lifestyle changes after the outbreak of COVID-19 have been assessed, and the impact of such changes on mental health was also explored among the general population in Mainland China. Noticeably, NPIs have modified some lifestyle behaviors positively and others negatively. Both unhealthy lifestyle behaviors and negative lifestyle changes were associated with lower SWB. Although about half of the participants reported no lifestyle changes, the percentages of reported favorable lifestyle changes were larger than the percentages of reported unfavorable lifestyle changes, especially in relation to the frequency of vegetable and fruit intake. However, the situation was the opposite when considering leisure-time physical exercise and screen time. Thus, it is possible that the sudden occurrence 
of COVID-19 made people reconsider their healthy lifestyle habits. In addition, the social or home isolation policy made people avoid public places and increase their indoor time, which may have increased their use of electronic media at home. Cognitive behavior therapy enables activity scheduling during home isolation and improves mental health [31].

Accordingly, unhealthy lifestyle behaviors were recorded among the Chinese population after the outbreak of COVID-19. For example, about $40 \%$ of the participants had inactive leisure-time physical exercise and about $90 \%$ had longer screen time. In addition, vegetable and fruit intake was less than 5 times/week for about $30 \%$ and $60 \%$ of the participants, respectively. However, it is not known whether such lifestyle patterns would persist during the COVID-19 pandemic or after the COVID-19 pandemic. Therefore, further studies to assess the lasting effects of the COVID-19 pandemic on lifestyle behaviors are warranted.

The findings of this study have added to the existing evidence that physical exercise is associated with mental well-being $[32,33]$. For example, a larger cross-sectional study indicated that sports and vigorous recreational activities were positively associated with emotional well-being even after adjusting for sex, social class, and health status [34]. In addition, active physical exercises were associated with reduced risk of mental health conditions such as depression and anxiety [35]. Similarly, during the SARS epidemic, increased exercise time was associated with decreased perceived stress and incidence of PTSD in the general population of Hong Kong [36]. However, increased exercise time did not significantly predict subjective well-being. A possible explanation could be that SWB may be associated with the intensity of physical exercise. Many studies demonstrated that vigorous physical exercises were positively associated with SWB, while moderate physical exercises were either not associated or negatively associated with SWB $[37,38]$. Another reason is that the environment for physical exercise may have a great impact on mental well-being [39]. Therefore, further studies about intensity of physical exercises under different environments are needed to fully elucidate the effects on wellbeing.

The finding that a higher frequency of vegetable and fruit intake was positively associated with subjective well-being is consistent with previous studies [40-42]. There is an urgent need to disseminate this health information to the public during the COVID-19 pandemic via the internet and health collaborators $[43,44]$. For example, Stranges et al [45] reported that the odds for low mental well-being were increased in those with decreasing fruit and vegetable intake. Furthermore, a systematic review of 61 studies indicated that higher total intake of fruits and vegetables may promote higher levels of optimism and reduce psychological distress, thereby having a positive influence on mental health [42]. Even though the total quantities of vegetable and fruit intake were not obtained in this study, we assumed that a higher frequency of intake may lead to higher total volume intake; thus, the former and the latter may have the same influence. Nevertheless, further studies are warranted to understand the association between mental health and quantities of vegetables and fruits consumed. The finding about the relationship between eating habits, like skipping breakfast, and well-being added to the existing evidence that skipping breakfast is associated with poorer physical and mental health outcomes [41,46,47]. For instance, breakfast skippers had significantly worse health-related quality of life both physically and mentally in a Taiwanese national representative sample [48]. In addition, a large cohort study indicated that an eating pattern characterized by skipping or delaying breakfast was associated with mood disorders among Australian adults [49]. However, the relationship between mental health and the manner in which breakfast is eaten needs further investigation.

In summary, this original preliminary study examined some positive and negative lifestyle changes due to the influence of the COVID-19 pandemic. It has revealed the pressing need to provide individuals, communities, and health agencies with information to help maintain healthy lifestyles to some degree while in isolation. Moreover, this study has contributed to the scant literature on the association between lifestyle behaviors and mental health during the COVID-19 pandemic. However, this study has several limitations. First, this study had a cross-sectional design and was conducted during the COVID-19 pandemic. Thus, causality relationships could not be inferred, and it is not clear whether the association between subjective well-being and lifestyle behaviors as well as their changes will last medium- and long-term. Second, precise information about lifestyle behaviors was difficult to collect before the start of the COVID-19 pandemic. Therefore, only perceived lifestyle changes were measured. Moreover, lifestyle behaviors and perceived changes were self-reported, thus these measurements may be susceptible to recall bias. Third, this study population had a high proportion of subjects aged 18 to 40 years (approximately 90\%) and a high proportion of participants had a higher education level. Whether the observed changes and associations are present in a more representative study population requires further exploration. Therefore, longitudinal studies with representative samples should be conducted during the COVID-19 pandemic to better understand the lasting effects of this pandemic on lifestyle behaviors and their changes.

\section{Acknowledgments}

We thank all the participants for their cooperation throughout the study. There was no funding for this study.

\section{Authors' Contributions}

$\mathrm{ZH}$ and XL contributed to analyzing data and writing the first original draft. ACK contributed to the editing of all versions of the manuscript. HX contributed to the editing of the first draft and provided supervision. All authors have read and agreed to the final draft of the manuscript. 


\section{Conflicts of Interest}

None declared.

\section{References}

1. Sohrabi C, Alsafi Z, O'Neill N, Khan M, Kerwan A, Al-Jabir A, et al. World Health Organization declares global emergency: A review of the 2019 novel coronavirus (COVID-19). Int J Surg 2020 Feb 26;76:71-76. [doi: 10.1016/j.ijsu.2020.02.034] [Medline: 32112977$]$

2. Paules CI, Marston HD, Fauci AS. Coronavirus Infections-More Than Just the Common Cold. JAMA 2020 Jan 23:1. [doi: 10.1001/jama.2020.0757] [Medline: $\underline{31971553]}$

3. Mahase E. China coronavirus: WHO declares international emergency as death toll exceeds 200. BMJ 2020 Jan 31;368:m408. [doi: 10.1136/bmj.m408] [Medline: 32005727]

4. Coronavirus disease (COVID-19) Pandemic. World Health Organization. URL: https://www.who.int/emergencies/diseases/ novel-coronavirus-2019 [accessed 2020-08-19]

5. Balanzá-Martínez V, Atienza-Carbonell B, Kapczinski F, De Boni RB. Lifestyle behaviours during the COVID-19 - time to connect. Acta Psychiatr Scand 2020 May;141(5):399-400 [FREE Full text] [doi: 10.1111/acps.13177] [Medline: 32324252]

6. Velten J, Bieda A, Scholten S, Wannemüller A, Margraf J. Lifestyle choices and mental health: a longitudinal survey with German and Chinese students. BMC Public Health 2018 May 16;18(1):632 [FREE Full text] [doi:

10.1186/s12889-018-5526-2] [Medline: 29769115]

7. Zaman R, Hankir A, Jemni M. Lifestyle Factors and Mental Health. Psychiatr Danub 2019 Sep;31(Suppl 3):217-220 [FREE Full text] [Medline: $\underline{\text { 31488729] }}$

8. Shah K, Kamrai D, Mekala H, Mann B, Desai K, Patel RS. Focus on Mental Health During the Coronavirus (COVID-19) Pandemic: Applying Learnings from the Past Outbreaks. Cureus 2020 Mar 25;12(3):e7405 [FREE Full text] [doi: 10.7759/cureus.7405] [Medline: 32337131]

9. Wang C, Pan R, Wan X, Tan Y, Xu L, McIntyre RS, et al. A longitudinal study on the mental health of general population during the COVID-19 epidemic in China. Brain Behav Immun 2020 Jul;87:40-48 [FREE Full text] [doi: 10.1016/j.bbi.2020.04.028] [Medline: 32298802]

10. Tan W, Hao F, McIntyre RS, Jiang L, Jiang X, Zhang L, et al. Is returning to work during the COVID-19 pandemic stressful? A study on immediate mental health status and psychoneuroimmunity prevention measures of Chinese workforce. Brain Behav Immun 2020 Jul;87:84-92 [FREE Full text] [doi: 10.1016/j.bbi.2020.04.055] [Medline: 32335200]

11. Wang C, Pan R, Wan X, Tan Y, Xu L, Ho CS, et al. Immediate Psychological Responses and Associated Factors during the Initial Stage of the 2019 Coronavirus Disease (COVID-19) Epidemic among the General Population in China. Int J Environ Res Public Health 2020 Mar 06;17(5):1 [FREE Full text] [doi: 10.3390/ijerph17051729] [Medline: 32155789]

12. Rajkumar RP. COVID-19 and mental health: A review of the existing literature. Asian J Psychiatr 2020 Apr 10;52:102066 [FREE Full text] [doi: 10.1016/j.ajp.2020.102066] [Medline: 32302935]

13. Torales J, O'Higgins M, Castaldelli-Maia JM, Ventriglio A. The outbreak of COVID-19 coronavirus and its impact on global mental health. Int J Soc Psychiatry 2020 Jun;66(4):317-320. [doi: 10.1177/0020764020915212] [Medline: 32233719]

14. Brooks SK, Webster RK, Smith LE, Woodland L, Wessely S, Greenberg N, et al. The psychological impact of quarantine and how to reduce it: rapid review of the evidence. Lancet 2020 Mar 14;395(10227):912-920. [doi: 10.1016/S0140-6736(20)30460-8] [Medline: 32112714 ]

15. GBD 2017 Risk Factor Collaborators. Global, regional, and national comparative risk assessment of 84 behavioural, environmental and occupational, and metabolic risks or clusters of risks for 195 countries and territories, 1990-2017: a systematic analysis for the Global Burden of Disease Study 2017. Lancet 2018 Nov 10;392(10159):1923-1994 [FREE Full text] [doi: 10.1016/S0140-6736(18)32225-6] [Medline: 30496105]

16. Rao S, Shah N, Jawed N, Inam S, Shafique K. Nutritional and lifestyle risk behaviors and their association with mental health and violence among Pakistani adolescents: results from the National Survey of 4583 individuals. BMC Public Health 2015 Apr 28;15:431 [FREE Full text] [doi: 10.1186/s12889-015-1762-x] [Medline: 25927931]

17. Chen P, Mao L, Nassis GP, Harmer P, Ainsworth BE, Li F. Coronavirus disease (COVID-19): The need to maintain regular physical activity while taking precautions. J Sport Health Sci 2020 Mar;9(2):103-104 [FREE Full text] [doi: 10.1016/j.jshs.2020.02.001] [Medline: 32099716]

18. Zhang L, Liu Y. Potential interventions for novel coronavirus in China: A systematic review. J Med Virol 2020 May;92(5):479-490 [FREE Full text] [doi: 10.1002/jmv.25707] [Medline: 32052466]

19. Dong L, Bouey J. Public Mental Health Crisis during COVID-19 Pandemic, China. Emerg Infect Dis 2020 Jul;26(7):1616-1618 [FREE Full text] [doi: 10.3201/eid2607.200407] [Medline: 32202993]

20. Galea S, Merchant RM, Lurie N. The Mental Health Consequences of COVID-19 and Physical Distancing: The Need for Prevention and Early Intervention. JAMA Intern Med 2020 Apr 10:2020. [doi: 10.1001/jamainternmed.2020.1562] [Medline: 32275292] 
21. Tran BX, Ha GH, Nguyen LH, Vu GT, Hoang MT, Le HT, et al. Studies of Novel Coronavirus Disease 19 (COVID-19) Pandemic: A Global Analysis of Literature. Int J Environ Res Public Health 2020 Jun 08;17(11):1-16 [FREE Full text] [doi: 10.3390/ijerph17114095] [Medline: 32521776]

22. Wjx. URL: https://www.wjx.cn [accessed 2020-08-19]

23. Ren YJ, Su M, Liu QM, Tan YY, Li LM, Lyu J. Validation of the Simplified Chinese-character Version of the International Physical Activity Questionnaire-Long Form in Urban Community-dwelling Adults: a Cross-sectional Study in Hangzhou, China. Biomed Environ Sci 2017 Apr;30(4):255-263 [FREE Full text] [doi: 10.3967/bes2017.035] [Medline: 28494835]

24. Haskell WL, Lee I, Pate RR, Powell KE, Blair SN, Franklin BA, et al. Physical activity and public health: updated recommendation for adults from the American College of Sports Medicine and the American Heart Association. Med Sci Sports Exerc 2007 Aug;39(8):1423-1434. [doi: 10.1249/mss.0b013e3180616b27] [Medline: 17762377]

25. Zhao W, Hasegawa K, Chen J. The use of food-frequency questionnaires for various purposes in China. Public Health Nutr 2002 Dec;5(6A):829-833. [doi: 10.1079/phn2002374] [Medline: 12638592]

26. Zimet GD, Powell SS, Farley GK, Werkman S, Berkoff KA. Psychometric characteristics of the Multidimensional Scale of Perceived Social Support. J Pers Assess 1990;55(3-4):610-617. [doi: 10.1080/00223891.1990.9674095] [Medline: 2280326]

27. Xu S, Qiu D, Hahne J, Zhao M, Hu M. Psychometric properties of the short-form UCLA Loneliness Scale (ULS-8) among Chinese adolescents. Medicine (Baltimore) 2018 Sep;97(38):e12373 [FREE Full text] [doi: 10.1097/MD.0000000000012373] [Medline: 30235699]

28. Hays RD, DiMatteo MR. A short-form measure of loneliness. J Pers Assess 1987;51(1):69-81. [doi: 10.1207/s15327752jpa5101 6] [Medline: $\underline{3572711]}$

29. Diener E, Suh EM, Lucas RE, Smith HL. Subjective well-being: Three decades of progress. Psychological Bulletin 1999;125(2):276-302. [doi: 10.1037/0033-2909.125.2.276]

30. Duan J. The application of General Well-Being Schedule in university students [Chinese]. Chinese Journal of Clinical Psychology 1996;4(1):56-57.

31. Ho CS, Chee CY, Ho RC. Mental Health Strategies to Combat the Psychological Impact of COVID-19 Beyond Paranoia and Panic. Ann Acad Med Singapore 2020 Mar 16;49(3):155-160 [FREE Full text] [Medline: $\underline{32200399]}$

32. McMahon EM, Corcoran P, O'Regan G, Keeley H, Cannon M, Carli V, et al. Physical activity in European adolescents and associations with anxiety, depression and well-being. Eur Child Adolesc Psychiatry 2017 Jan;26(1):111-122. [doi: 10.1007/s00787-016-0875-9] [Medline: 27277894]

33. Haapasalo V, de Vries H, Vandelanotte C, Rosenkranz RR, Duncan MJ. Cross-sectional associations between multiple lifestyle behaviours and excellent well-being in Australian adults. Prev Med 2018 Nov;116:119-125. [doi: 10.1016/j.ypmed.2018.09.003] [Medline: $\underline{30218725]}$

34. Steptoe A, Butler N. Sports participation and emotional wellbeing in adolescents. Lancet 1996 Jun 29;347(9018):1789-1792. [doi: 10.1016/s0140-6736(96)91616-5] [Medline: $\underline{\text { 8667922] }}$

35. Ströhle A. Physical activity, exercise, depression and anxiety disorders. J Neural Transm (Vienna) 2009 Jun;116(6):777-784. [doi: 10.1007/s00702-008-0092-x] [Medline: 18726137]

36. Lau JTF, Yang X, Tsui HY, Pang E, Wing YK. Positive mental health-related impacts of the SARS epidemic on the general public in Hong Kong and their associations with other negative impacts. J Infect 2006 Aug;53(2):114-124 [FREE Full text] [doi: 10.1016/j.jinf.2005.10.019] [Medline: 16343636]

37. Wicker P, Frick B. Intensity of physical activity and subjective well-being: an empirical analysis of the WHO recommendations. J Public Health (Oxf) 2017 Jun 01;39(2):e19-e26. [doi: 10.1093/pubmed/fdw062] [Medline: 27412174]

38. Costigan SA, Lubans DR, Lonsdale C, Sanders T, Del Pozo Cruz B. Associations between physical activity intensity and well-being in adolescents. Prev Med 2019 Aug;125:55-61. [doi: 10.1016/j.ypmed.2019.05.009] [Medline: 31125627]

39. Thompson Coon J, Boddy K, Stein K, Whear R, Barton J, Depledge MH. Does participating in physical activity in outdoor natural environments have a greater effect on physical and mental wellbeing than physical activity indoors? A systematic review. Environ Sci Technol 2011 Mar 01;45(5):1761-1772. [doi: 10.1021/es102947t] [Medline: 21291246]

40. Ocean N, Howley P, Ensor J. Lettuce be happy: A longitudinal UK study on the relationship between fruit and vegetable consumption and well-being. Soc Sci Med 2019 Feb;222:335-345 [FREE Full text] [doi: 10.1016/j.socscimed.2018.12.017] [Medline: 30626498]

41. Lesani A, Mohammadpoorasl A, Javadi M, Esfeh JM, Fakhari A. Eating breakfast, fruit and vegetable intake and their relation with happiness in college students. Eat Weight Disord 2016 Dec;21(4):645-651. [doi: 10.1007/s40519-016-0261-0] [Medline: 26928281]

42. Głąbska D, Guzek D, Groele B, Gutkowska K. Fruit and Vegetable Intake and Mental Health in Adults: A Systematic Review. Nutrients 2020 Jan 01;12(1):1-34 [FREE Full text] [doi: 10.3390/nu12010115] [Medline: 31906271]

43. Tran BX, Dang AK, Thai PK, Le HT, Le XTT, Do TTT, et al. Coverage of Health Information by Different Sources in Communities: Implication for COVID-19 Epidemic Response. Int J Environ Res Public Health 2020 May 20;17(10):3577 [FREE Full text] [doi: 10.3390/ijerph17103577] [Medline: 32443712] 
44. Tran BX, Phan HT, Nguyen TPT, Hoang MT, Vu GT, Thi Lei H, et al. Reaching further by Village Health Collaborators: The informal health taskforce of Vietnam for COVID-19 responses. J Glob Health 2020 Jun;10(1):010354 [FREE Full text] [doi: 10.7189/jogh.10.010354] [Medline: $\underline{\text { 32509285] }}$

45. Stranges S, Samaraweera PC, Taggart F, Kandala N, Stewart-Brown S. Major health-related behaviours and mental well-being in the general population: the Health Survey for England. BMJ Open 2014 Sep 19;4(9):e005878 [FREE Full text] [doi: 10.1136/bmjopen-2014-005878] [Medline: 25239293]

46. Rong S, Snetselaar LG, Xu G, Sun Y, Liu B, Wallace RB, et al. Association of Skipping Breakfast With Cardiovascular and All-Cause Mortality. J Am Coll Cardiol 2019 Apr 30;73(16):2025-2032 [FREE Full text] [doi: 10.1016/j.jacc.2019.01.065] [Medline: 31023424]

47. Park S, Rim SJ, Lee JH. Associations between dietary behaviours and perceived physical and mental health status among Korean adolescents. Nutr Diet 2018 Nov;75(5):488-493. [doi: 10.1111/1747-0080.12444] [Medline: 29978549]

48. Huang C, Hu H, Fan Y, Liao Y, Tsai P. Associations of breakfast skipping with obesity and health-related quality of life: evidence from a national survey in Taiwan. Int J Obes (Lond) 2010 Apr;34(4):720-725. [doi: 10.1038/ijo.2009.285] [Medline: 20065977]

49. Wilson JE, Blizzard L, Gall SL, Magnussen CG, Oddy WH, Dwyer T, et al. An eating pattern characterised by skipped or delayed breakfast is associated with mood disorders among an Australian adult cohort. Psychol Med 2019 Oct 16:1-11. [doi: 10.1017/S0033291719002800] [Medline: $\underline{31615586]}$

\author{
Abbreviations \\ COVID-19: coronavirus disease \\ FFQ-25: Food Frequency Questionnaire \\ GWS: General Wellbeing Schedule \\ NPI: nonpharmacological intervention \\ OR: odds ratio \\ PSS: perceived social support \\ PSSS: Perceived Social Support Scale \\ PTSD: posttraumatic stress disorder \\ SARS: severe acute respiratory syndrome \\ SWB: subjective well-being \\ ULS-8: University of California, Los Angeles Loneliness Scale \\ WHO: World Health Organization
}

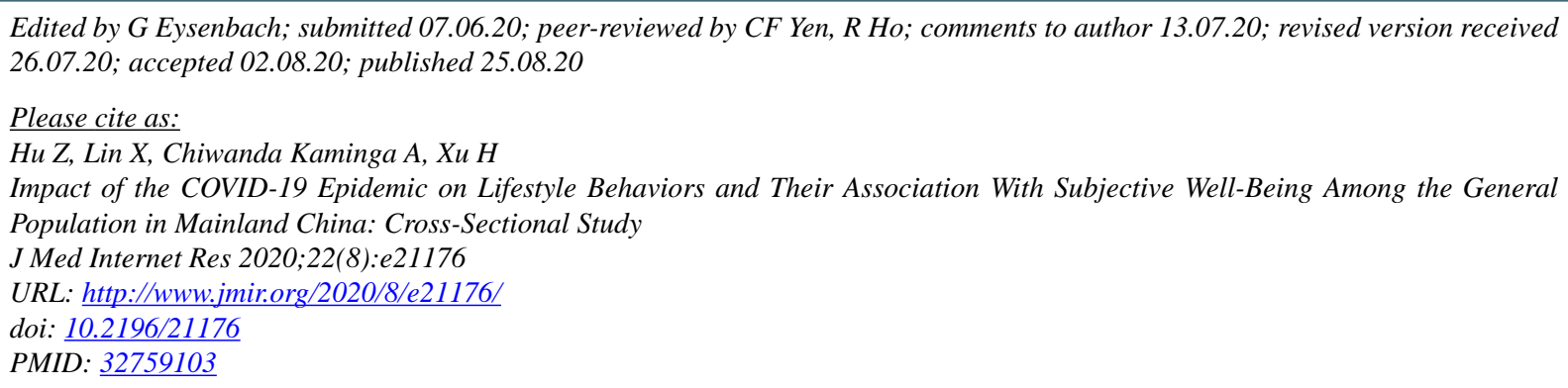

(CZhao Hu, Xuhui Lin, Atipatsa Chiwanda Kaminga, Huilan Xu. Originally published in the Journal of Medical Internet Research (http://www.jmir.org), 25.08.2020. This is an open-access article distributed under the terms of the Creative Commons Attribution License (https://creativecommons.org/licenses/by/4.0/), which permits unrestricted use, distribution, and reproduction in any medium, provided the original work, first published in the Journal of Medical Internet Research, is properly cited. The complete bibliographic information, a link to the original publication on http://www.jmir.org/, as well as this copyright and license information must be included. 